RASĀYAN J. Chem.

Vol. 13 | No. 4 |2616-2625| October - December | 2020 ISSN: 0974-1496 | e-ISSN: 0976-0083 | CODEN: RJCABP

\title{
SYNTHESIS AND CHARACTERIZATIONS OF A VERSATILE SILICA INCORPORATED MAGNESIUM-ZINC OXIDE PHOTOCATALYST
}

\author{
M. Athira Chandran ${ }^{1}$, N. Amal ${ }^{1}$, K. M. Sreedhar ${ }^{2}$, G. Sivasubramanian ${ }^{1}$ \\ and K. M. Sreekanth ${ }^{1, *}$ \\ ${ }^{1}$ Department of Sciences, Amrita School of Engineering, Amrita Vishwa Vidyapeetham, \\ Coimbatore, India - 641112 \\ ${ }^{2}$ Department of Chemistry, Amrita School of Arts \& Sciences, Amrita Vishwa Vidyapeetham, \\ Amritapuri, India - 690525 \\ *E-mail:km_sreekanth@cb.amrita.edu
}

\begin{abstract}
Magnesium incorporated silicon dioxide-zinc oxide photocatalyst was synthesized. Structural properties were investigated by x-ray diffraction studies. These studies revealed the amorphous nature of the catalyst. The ultraviolet-visible spectroscopic analysis gave the bandgap variation from 2.4 to $2.6 \mathrm{eV}$ with doping concentration. Surface morphology study, elemental analysis and thermal analysis were also carried out. Photocatalytic activities were followed by employing an ultraviolet-visible spectrophotometer. Photocatalytic reduction of chromium (VI) was studied using the catalyst under sunlight and ultraviolet radiation. This catalyst showed enhanced catalytic activity for the reduction of chromium (VI) and the degradation of methylene blue. The sample, $10 \%$ magnesiumenriched catalyst showed the highest photocatalytic activity. Under sunlight, photocatalytic reduction of chromium (VI) was very rapid when compared with that under ultraviolet radiation.
\end{abstract}

Keywords: Photocatalytic Activity, Metal Oxide Semiconductor, Chromium, Methylene Blue, Bandgap

(C) RASĀYAN. All rights reserved

\section{INTRODUCTION}

Mother Nature inherits a unique encompassing style that has worked for the benefit of all living beings at dimensions that have now been replicated and webbed across this world under the common name "nano" and practically delivered in the form of "nanotechnology". "There is plenty of rooms at the bottom" are the famous words of Richard Feynman which has galvanized scientists across the globe to manipulate atoms and get desired molecules that exhibit multi-functionality. Nano-materials are different from micro materials, in that they follow quantum mechanics whereas the other follows Newtonian mechanics. This difference in working gives drastically different properties for nano-materials when compared with micro materials. Metallic and metal oxide nanoparticles have a plethora of applications in the service of mankind. Nanoparticles exhibit unique properties due to their very small size, shape and surface to volume ratio. ${ }^{1-8}$

The industrial revolution and the globalization that followed have pushed the world to the brink of nonexistence. This appealing situation has forced even the most technologically advanced nations to rethink waste remediation, water purification, and clean air. India is the second-most populous country in the world and has a considerable presence in the textile, dyeing and bleaching industrial sectors of the world. Water contamination is one of the most common problems faced by industries and society. Most of the dyes used in the dyeing industry can create environmental issues and hence their degradation becomes important. It is assumed that the degradation processes are benign and are relatively safe for man and the environment. ${ }^{6-17}$

The heterogeneous photocatalysis using semiconductor nanoparticles or thin films is a practical solution for chromium (VI) reduction and dye degradation. Many research and industrial applications are progressing for a strong remedy to this pollution. But many of the attempts failed due to high expenditure Rasayan J. Chem., 13(4), 2616-2625(2020) http://dx.doi.org/10.31788/ RJC.2020.1345859

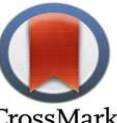


and other demerits. ${ }^{12}$ Bacterial degradation is a popular method that became inefficient due to the emission of new toxic elements. Activated carbon faced problems for this application due to the huge price for waste disposal. ${ }^{2}$ So, it is high time to find a solution that is highly efficient and practical for contaminated water resources. Heterogeneous photocatalysis, a productive and powerful technique for total mineralization of pollutants from the environment is followed in this work. ${ }^{3}$ The photocatalyst is a material absorbing light, producing electron-hole pair and initiates a chemical reaction without being consumed. ${ }^{17-23}$

Semiconductor metal oxide-based photocatalysts act as activators catalyzing the oxidation process. Degradation of organic dyes in polluted water can be performed at low cost and with other tunable properties by photocatalytic treatment without any notable loss in photocatalytic activity ${ }^{24}$. Comparing to bulk materials, semiconductor metal oxides in nano-scale possess tremendous functionalities due to quantum confinement, which gives them unique structural, electronic, antimicrobial, optical, anti-tumor, anti-inflammatory and wound healing properties. Among the trending research on metal oxide semiconductors, the search for photocatalyst material with high performance under solar illumination is a highlighted topic. This is because of its abundance and eco-friendly nature ${ }^{1}$. A photocatalyst provides a reaction path that is green, sustainable and non-toxic. Among the metal oxide semiconductors, $\mathrm{TiO}_{2}, \mathrm{ZnO}$ and $\mathrm{WO}_{3}$ are used as the best photocatalyst because of their high activity, low cost, insolubility in water, stability and non-toxicity. ${ }^{4}$ There are a considerable number of methods for separation and accretion of pollutants but unable to degrade them. Photocatalytic activity is a perfect solution for such degradation. Several studies showed that $\mathrm{TiO}_{2}$ as a worthy photocatalyst. The potentiality of other metal oxides as photocatalysts is an ongoing research topic. In this area, $\mathrm{ZnO}$ is a promising photocatalyst for the degradation of organic pollutants. There are many reports during the last few years on the degradation of dye-based pollutants mediated by $\mathrm{ZnO} .^{5}$

Zinc oxide possesses an energy gap, $3.3 \mathrm{eV}$ and an exciton binding energy, $60 \mathrm{meV}$ which enables it to be used extensively for solar cells, sensors, LEDs, photocatalysis, UV detectors and FETs. ${ }^{23}$ Changing the properties into our desired form is simply achieved through bandgap engineering. This is achieved by doping $\mathrm{ZnO}$ by metals, non-metals and transition metal ions. Doping not only can cause an impact on optical, catalytic and electrical properties but also can develop new structural designs. ${ }^{13,23}$ There are reports on the photo catalytically active Mg-doped zinc oxide nano-crystals ${ }^{1}$. In the current work, preparation and characterization of the photocatalyst, magnesium doped silica-zinc oxide nanocomposite, and photodegradation of $\mathrm{Cr}$ (VI) and methylene blue using this catalyst are exposed. The impact of reaction parameters like time, the concentration of the dopants and exposure to radiation are investigated.

\section{EXPERIMENTAL}

\section{Materials}

The materials used include foxtail millet (spikelet), nitric acid, zinc sulphate, $\mathrm{ZnSO}_{4} \cdot 7 \mathrm{H}_{2} \mathrm{O}$, sodium hydroxide, $\mathrm{NaOH}$, magnesium sulphate heptahydrate, $\mathrm{MgSO}_{4} \cdot 7 \mathrm{H}_{2} \mathrm{O}$, cetyl trimethylammonium bromide (CTAB), de-ionized water and acetone. The chemicals were of purity $\geq 96 \%$, from Sigma-Aldrich, AR grade and used as such.

\section{Preparation of Foxtail Millet Husk Ash}

Foxtail millet, obtained locally, Ettimadai, Coimbatore, India, was cleaned with distilled water for removing the adhered impurities and then dried in a hot air oven. The husk was removed from the millet by grinding it in a domestic blender and then by winnowing. The separated husk was washed thoroughly with a copious amount of de-ionized water and dried in a hot air oven for 6 hours. The husk thus obtained was treated with $1 \mathrm{M} \mathrm{HNO}_{3}$ and continued agitation for one day to remove all the metallic particles originated from the soil and then treated with distilled water and dried in a hot air oven at $333 \mathrm{~K}$ for $12 \mathrm{~h}$. The neat husk was calcinated in a muffle furnace at $973 \mathrm{~K}$ for $6 \mathrm{~h}$ so that the organic contents were removed. The resulting white powder (ash) was used for further work. ${ }^{6}$ Silica can undergo a structural transformation which depends on the time and temperature of combustion. At $550{ }^{\circ} \mathrm{C}-800{ }^{\circ} \mathrm{C}$, amorphous ash and at temperatures above this, crystalline ash is produced. This type of silica has different properties.

\section{Preparation of Sodium Silicate From the Husk Ash}


RASĀYAN J. Chem.

Vol. 13 | No. 4 |2616-2625| October - December | 2020

A simple chemical method was followed to produce silica from the husk ash. The solubility of silica is very low at $p^{\mathrm{H}}$ less than 10 and increases sharply at $p^{\mathrm{H}}$ greater than 10 . This solubility behavior enables silica to extract in a pure state from millet husk ash dissolving under alkaline conditions. This method based on alkaline solubility is cost-effective than the current smelting method. ${ }^{7}$

A $0.4 \mathrm{M}, 200 \mathrm{~mL}$ solution of $\mathrm{NaOH}$ was prepared. This solution was heated to $70{ }^{\circ} \mathrm{C}$ in a microwave oven into which the prepared ash of millet husk was added. The solution was heated for better dissolution of the ash into $\mathrm{NaOH}$ solution. This alkaline solution was kept under continuous stirring over a magnetic stirrer at $800 \mathrm{rpm}$ for 12 hours at room temperature. It was then filtered using a Whatman No. 40 filter paper. The filtrate obtained is a solution of sodium silicate containing $\mathrm{NaOH}$ also.

\section{Synthesis of the Photocatalyst Nanocomposite}

The method employed for the production of the nanocomposite is the mechanical-assisted chemical coprecipitation technique. ${ }^{13}$ For producing silica incorporated zinc oxide, a solution of $\mathrm{ZnSO}_{4} \cdot 7 \mathrm{H}_{2} \mathrm{O}$ was prepared in the required concentration and stirred with a solution of sodium silicate, prepared from the husk, over a magnetic stirrer, after adding CTAB. The stirring was extended for 5 hours. The precipitate thus obtained was thoroughly cleaned using de-ionized water and acetone and dried in a hot air oven. It was then heated in a muffle furnace at $150{ }^{\circ} \mathrm{C}$ for ten hours to form $\mathrm{SiO}_{2}-\mathrm{ZnO}$. The sample was then cooled to room temperature and then grounded for size reduction. The Mg-doped samples were prepared following the same method taking 1,5 , or 10 mole $\%$ of magnesium sulphate heptahydrate also, separately.

\section{Characterization}

The $\mathrm{Mg}$ incorporated $\mathrm{SiO}_{2}-\mathrm{ZnO}$ nanocomposite was characterized by different techniques. To understand the bandgap variation with doping, optical studies using UV-visible spectrophotometer was performed. To analyze the composition of ash, XRF analysis was performed using model AXIOS ${ }^{\circledR}$ from PAN analytical. Weight loss for white ash as a function of temperature was studied using TGA measurements on a Nietzsche STA449F1 programmable thermo balance. FE-SEM images of zinc oxide nanoparticles and the nanocomposite were obtained using a JSM-JEOL 6390 FE-SEM instrument. Structural properties of ash and the nanocomposite were obtained from Philip PW1700 XRD.

\section{Photocatalytic Applications}

\section{Instrumentation of the Photocatalytic Reactor}

A self-assembled photoreactor, which is cheaper and a powerful instrument, was used for this work ${ }^{1}$. The sketch of the reactor is as in Fig.-1. It has an insulated cabin with a window. The cabin can be maintained at the desired temperature using an air heat-exchanger attached to the cabin. Inside of the cabin is decorated with UV LED strips of $0.2 \mathrm{~W}$ in series, providing an enclosed ultraviolet environment for photocatalytic reaction. The arrangement has a magnetic stirrer at the bottom.

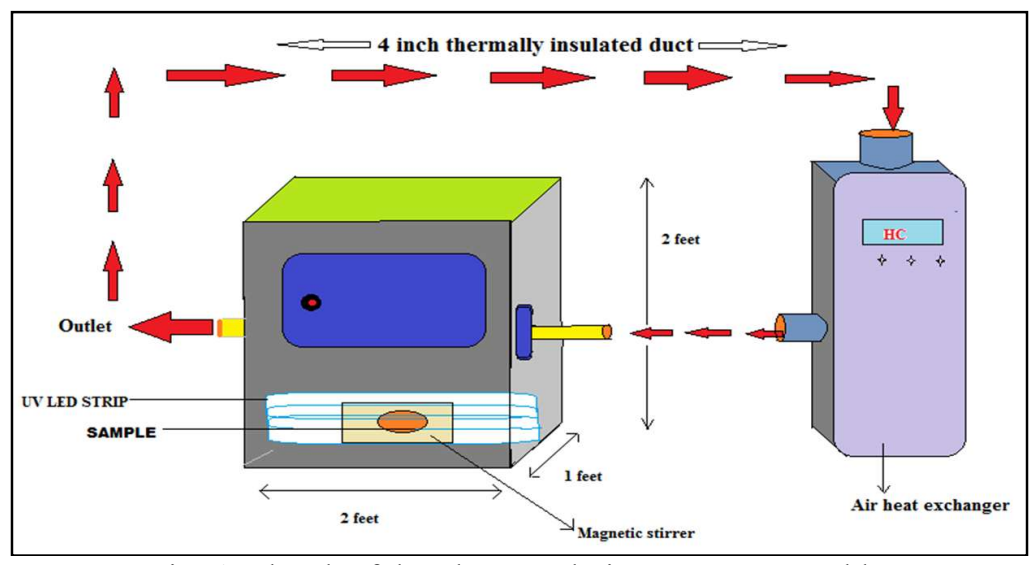

Fig.-1: Sketch of the Photocatalytic Reactor Assembly

\section{Reduction of Chromium (VI)}


RASĀYAN J. Chem.

Vol. 13 | No. 4 |2616-2625| October - December | 2020

It was performed in UV, RGB 300 UV LED strip with $150 \mathrm{~V}-265 \mathrm{~V} \mathrm{AC}$ input. A series of experiments were conducted using the prepared three different samples of $\mathrm{Mg}_{-} \mathrm{SiO}_{2}-\mathrm{ZnO}$ nanocomposite as the photocatalyst. $100 \mathrm{~mL}, 50 \mathrm{ppm}$ chromium (VI) solution was prepared to add $0.01 \mathrm{M}$ oxalic acid as the hole-scavenger. $20 \mathrm{mg}$ of the catalyst was dropped and shaken at $600 \mathrm{rpm}$. Initially, the solution was stirred in dark for $15 \mathrm{~min}$. The sample was collected at each half an hour during photoreduction to perform UV-Vis spectroscopic analysis. The indicator used for the photocatalytic reaction was Biphenyl carbazide. Residual chromium (VI) concentration was estimated at $540 \mathrm{~nm}$ with UV-Vis spectrophotometer of SAFIRE Scientific Company. The same experiment was repeated under sunlight with all three catalysts to study the photocatalytic reduction of $\mathrm{Cr}(\mathrm{VI})$.

\section{Degradation of Methylene Blue}

Degradation of methylene blue was performed in sunlight using the nanocomposite as the photocatalyst. $100 \mathrm{~mL}$ of $0.01 \%$ of methylene blue solution was prepared. $20 \mathrm{mg}$ of the photocatalyst was added and shaken at $600 \mathrm{rpm}$. The sample was collected at each half an hour and the concentration of residual methylene blue was estimated using UV-Vis spectrophotometer.

\section{RESULTS AND DISCUSSION}

Optical studies were done at room temperature using a UV-visible spectrophotometer. Absorbance spectra of $\mathrm{Mg}_{-} \mathrm{SiO}_{2}-\mathrm{ZnO}$ against wavelength are as presented in Fig.-2. As doping concentration increases, the wavelength of absorption decreases that indicates an increase in the band gap ${ }^{14-16}$. The plot shows that the material has visible light absorbance above $350 \mathrm{~nm}$.

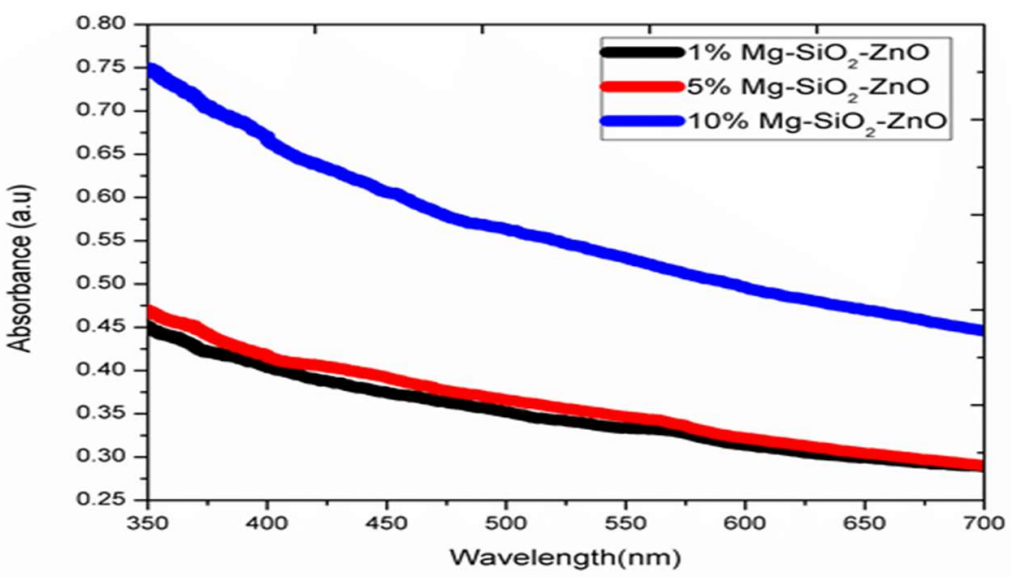

Fig.-2: Absorbance Spectra of $\mathrm{Mg}-\mathrm{SiO}_{2}-\mathrm{ZnO}$

The direct bandgap of $\mathrm{Mg}-\mathrm{SiO}_{2}-\mathrm{ZnO}$ is determined based on Tauc's method, Fig.-3. It was reported the bandgap of $\mathrm{ZnO}$ increases when doped with $\mathrm{Mg}$ and it still increases with the concentration of the dopant ${ }^{1}$. But, the introduction of $\mathrm{SiO}_{2}$ into $\mathrm{Mg}-\mathrm{ZnO}$ causes a reduction in the bandgap.

Table-1: Bandgap Determined From Tauc Plot

\begin{tabular}{l|l}
\hline \multicolumn{1}{c|}{ Sample } & \multicolumn{1}{c}{ Bandgap } \\
\hline $1 \% \mathrm{Mg}-\mathrm{SiO}_{2}-\mathrm{ZnO}$ & $2.36 \mathrm{eV}$ \\
\hline $5 \% \mathrm{Mg}-\mathrm{SiO}_{2}-\mathrm{ZnO}$ & $2.49 \mathrm{eV}$ \\
\hline $10 \% \mathrm{Mg}-\mathrm{SiO}_{2}-\mathrm{ZnO}$ & $2.58 \mathrm{eV}$ \\
\hline
\end{tabular}

The bandgap determined from the Tauc plot is presented in Table-1 and the bandgap of the composite is less than that of the pure $\mathrm{ZnO}$. There is an increase in bandgap as the doping concentration of $\mathrm{Mg}$ increases, Fig.-3. This behavior is due to the defects introduced after $\mathrm{Mg}^{2+}$ replaced $\mathrm{Zn}^{2+}$ while entering $\mathrm{ZnO}$ lattice ${ }^{8}$. Owing to the less electron affinity of $\mathrm{MgO}$ compared to $\mathrm{ZnO}$, the contribution of electrons 
RASĀYAN J. Chem.

Vol. 13 | No. 4 |2616-2625| October - December | 2020

by $\mathrm{Mg}$ dopant is higher. So, the location of the Fermi level is higher compared to the undoped sample. Hence the blue shift or increase in the bandgap.

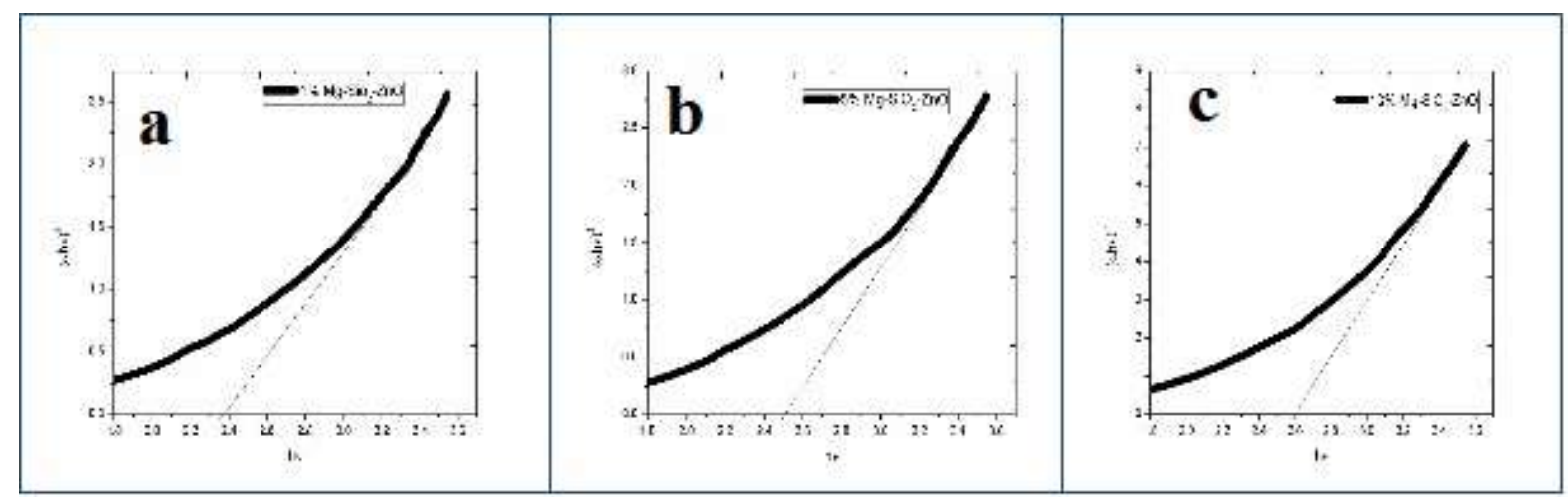

Fig.-3:Optical Absorption Spectra (Tauc Plot) of (a)1 \% Mg-SiO $2-\mathrm{ZnO},(\mathrm{b}) 5 \% \mathrm{Mg}-\mathrm{SiO}_{2}-\mathrm{ZnO}$,

(c) $10 \% \mathrm{Mg}_{-} \mathrm{SiO}_{2}-\mathrm{ZnO}$

Elemental compositions of the prepared raw husk, acid-washed husk and husk ash were obtained by XRF analysis as shown in Table-2. It gives the composition of the inorganic components of the samples. Organic components are the major part of the husk which consists of lignin, cellulose and hemicellulose. ${ }^{6}$ The result shows that $23.985 \%$ of the total weight is of inorganic components, out of which $16.82 \%$ is silica. Acid-treated husk has a total of $21.086 \%$ of inorganic components. Here there is a reduction of all the metals compared to the raw sample as expected. $15.665 \%$ of the total sample is of silica. A reduction in the amount of silica of this sample compared to the raw sample is due to leaching. The unbound silica in the sample has been washed off. So, there is a reduction from $16.83 \%$ to $15.665 \%$. The ash contains silica as the only major component of about $91.122 \%$. Other inorganic elements like $\mathrm{Al}, \mathrm{Ti}, \mathrm{Fe}, \mathrm{Mn}, \mathrm{Mg}$, $\mathrm{Ca}, \mathrm{Na}, \mathrm{K}$, and $\mathrm{P}$ are present only in trace amounts.

Table-2: The XRF Data of Inorganic Components

\begin{tabular}{c|c|c|c}
\hline $\begin{array}{c}\text { Metal } \\
\text { Oxides }\end{array}$ & $\begin{array}{c}\text { Raw Husk } \\
\text { (Wt. \%) }\end{array}$ & $\begin{array}{c}\text { Acid Washed Husk } \\
\text { (Wt. \%) }\end{array}$ & $\begin{array}{c}\text { Ash } \\
\text { (Wt. \%) }\end{array}$ \\
\hline $\mathrm{SiO}_{2}$ & 16.82 & 15.665 & 91.122 \\
\hline $\mathrm{Al}_{2} \mathrm{O}_{3}$ & 2.56 & 1.85 & 1.349 \\
\hline $\mathrm{Fe}_{2} \mathrm{O}_{3}$ & 0.475 & 0.376 & 0.825 \\
\hline $\mathrm{TiO}_{2}$ & 0.541 & 0.301 & 0.069 \\
\hline $\mathrm{MnO}$ & 0.011 & 0.001 & 0.025 \\
\hline $\mathrm{MgO}$ & 0.853 & 0.504 & 1.43 \\
\hline $\mathrm{CaO}$ & 0.322 & 0.238 & 0.372 \\
\hline $\mathrm{Na}_{2} \mathrm{O}$ & 0.378 & 0.377 & 0.309 \\
\hline $\mathrm{K}_{2} \mathrm{O}$ & 0.842 & 0.684 & 2.005 \\
\hline $\mathrm{P}_{2} \mathrm{O}_{5}$ & 1.183 & 1.090 & 2.490 \\
\hline $\mathrm{Total}$ & 23.985 & 21.086 & 100 \\
\hline
\end{tabular}

TGA shows the weight loss of the sample with an increase in temperature. The weight loss of the raw husk up to $700{ }^{\circ} \mathrm{C}$ was studied, Fig.-4. The weight loss observed till $100{ }^{\circ} \mathrm{C}$ is due to the loss of water content of the sample and after $100^{\circ} \mathrm{C}$, there is a steady decrease in weight up to $250{ }^{\circ} \mathrm{C}$. After this, there is a steep decrease from $250{ }^{\circ} \mathrm{C}$ to $350{ }^{\circ} \mathrm{C}$. This drastic weight loss is due to the burning of the organic components of the husk, $80 \%$ to $40 \%$ of the weight gets reduced at this temperature range. Finally, 75.47 $\%$ of the sample gets pyrolyzed at $700{ }^{\circ} \mathrm{C}$. This is the organic contents of the raw husk that gets vanished at $700{ }^{\circ} \mathrm{C}$.

The particle size of the sample and shape could be determined using an FE-SEM image. ZnO, Fig.-5, shows an agglomerated nano-flake structure. It shows a particle size of $201.8 \mathrm{~nm}$ and $266.4 \mathrm{~nm}$ at $1 \mu \mathrm{m}$ special resolution. The FE-SEM image of $1 \% \mathrm{Mg}_{-} \mathrm{SiO}_{2}-\mathrm{ZnO}$, Fig.-6, shows a more agglomerated image and not a flake structure. A different shape of particles is observed in this nanocomposite. 
RASĀYAN J. Chem.

Vol. 13 | No. 4 |2616-2625| October - December | 2020

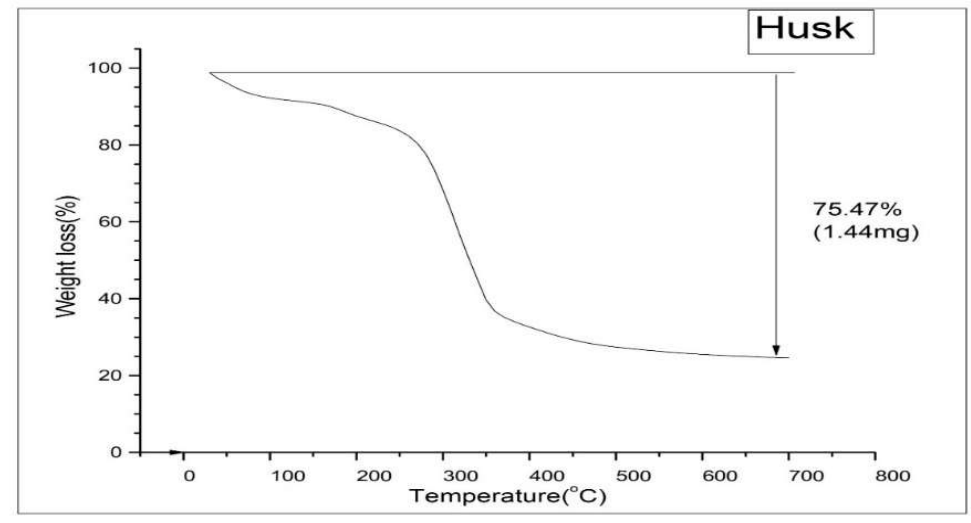

Fig.-4: TGA Plot of Husk

The EDX image, Fig.-7, shows the elements present in the sample. The electron beam is used for this surface analysis and characteristic X-rays are produced representing the elements present in the sample. Fig.-7a shows the sample contains zinc and oxygen as a major component and the Fig.-7b shows that the elements $\mathrm{Zn}, \mathrm{O}, \mathrm{Si}$, and $\mathrm{Mg}$ are present in the sample.

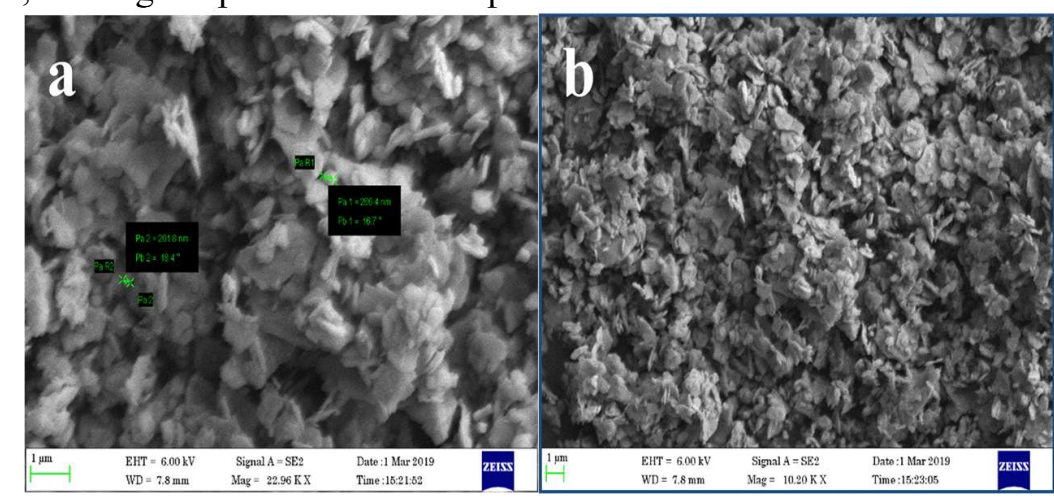

Fig.-5: FESEM Image of $\mathrm{ZnO}$ at Two Different Magnifications

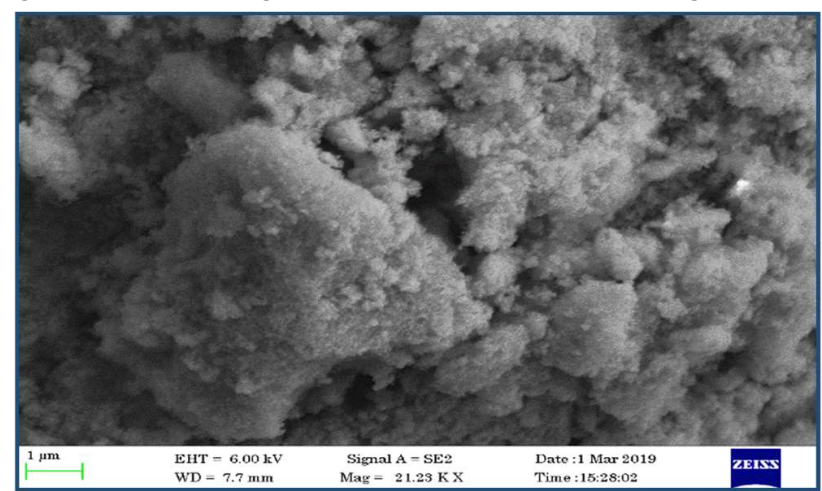

Fig.-6: FESEM Image of $1 \% \mathrm{Mg}_{-} \mathrm{SiO}_{2}-\mathrm{ZnO}$

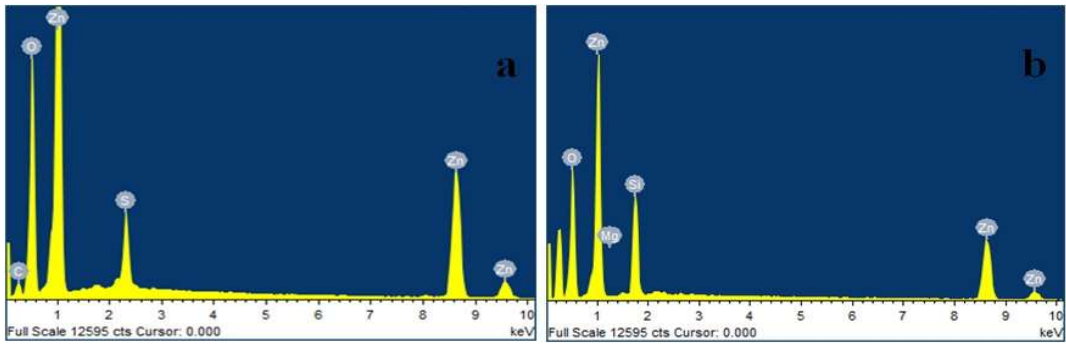

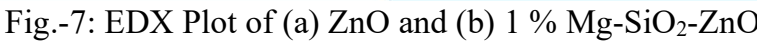

2621 
RASĀYAN J. Chem.

Vol. 13 | No. 4 |2616-2625| October - December | 2020

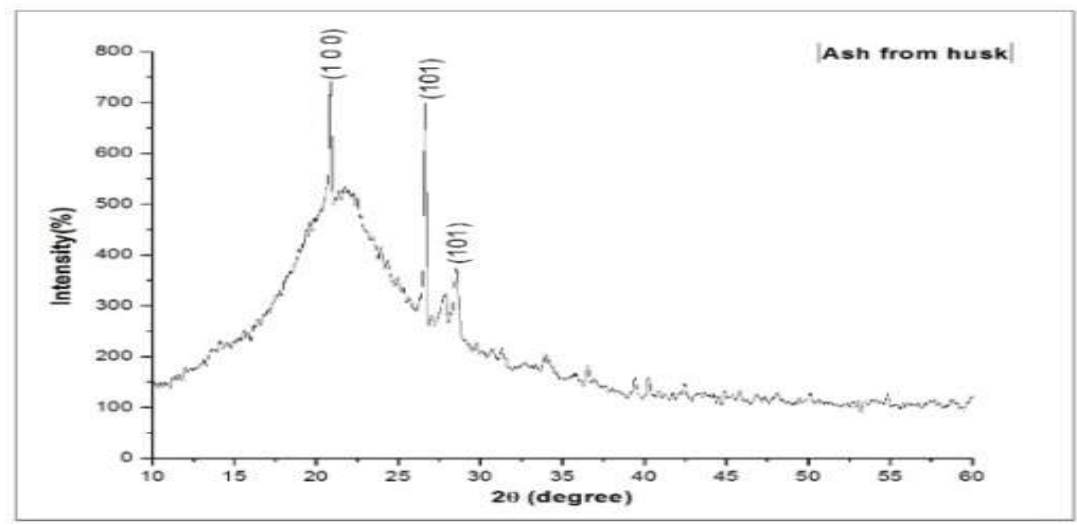

Fig.-8: XRD of Ash From the Husk

Ash from the husk contains silica as the major component. This silica belongs to the category of opaline silica. Opaline silica has amorphous as well as crystalline nature. The XRD, Fig.-8, clearly indicates the presence of opaline silica. The crystalline peak (100) at $20.8^{0}$ and peak (101) at $28.68^{0}$ corresponds to crystalline opaline silica. The crystalline peak (101) at $26.5^{\circ}$ corresponds to that of quartz. The broad peak in between is due to the amorphous opaline silica ${ }^{26}$. Due to the incorporation of amorphous silica into zinc oxide, the crystalline nature of zinc oxide has changed, Fig.-9. This figure shows the amorphous nature of the nanocomposite. A broad peak between $20^{\circ}$ and $40^{\circ}$ may correspond to the amorphous zinc oxide nanocomposite.

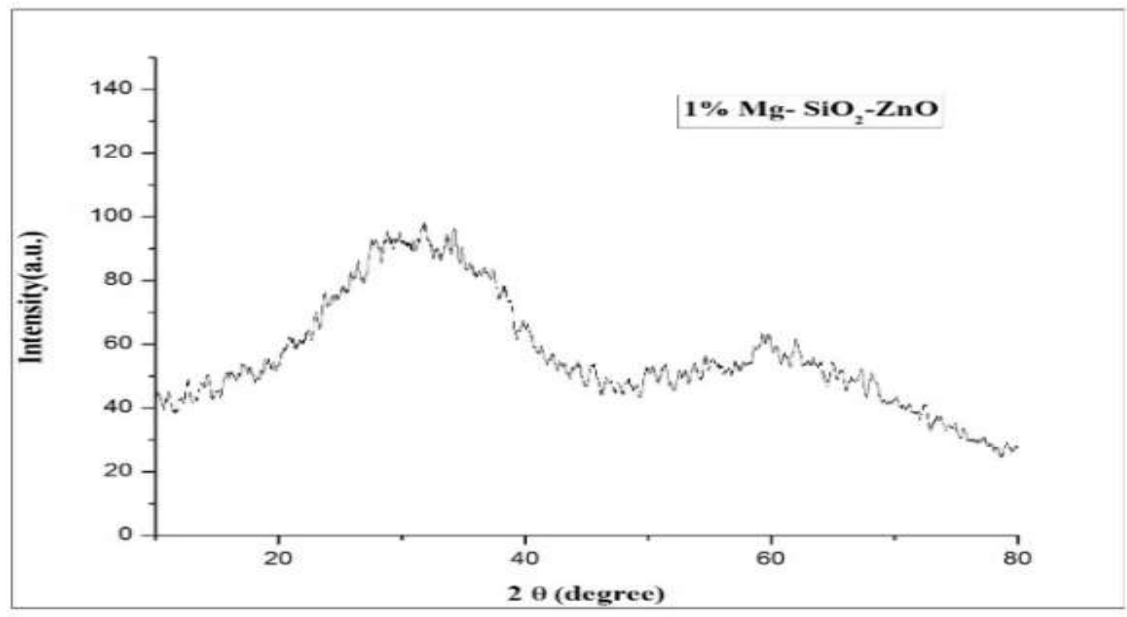

\section{Photocatalytic Study}

Fig.-9: XRD of $1 \% \mathrm{Mg}$-doped $\mathrm{SiO}_{2}-\mathrm{ZnO}$

The irradiation of UV light onto the sample causes the excitation of electrons from conduction band to valance band leaving holes in valance band ${ }^{25}$. Concerning SHE, the reduction potential of chromium (VI) /chromium (III) is $1.33 \mathrm{~V}$. A catalyst that has a bandgap above this can reduce $\mathrm{Cr}$ (VI) ${ }^{25}$. The $\mathrm{Cr}(\mathrm{VI})$ peak at $\sim 540 \mathrm{~nm}$ is reduced at a faster rate with the increase in doping concentration, Fig.-10, under UV ${ }^{1}$. The 1 $\%$ nanocomposite completely reduced $\mathrm{Cr}(\mathrm{VI})$ in $4 \mathrm{~h}$ whereas $5 \%$ catalyst completed the reduction within $180 \mathrm{~min}$. It only took $150 \mathrm{~min}$ for the reduction using $10 \%$ catalyst. This is because as doping concentration increases, the bandgap increases, and the blue shift is observed ${ }^{1}$.

When the same experiment was carried out under sunlight, a faster reduction of $\mathrm{Cr}$ (VI) was observed, Fig.-11. The $1 \%$ composite reduced the toxic element within $120 \mathrm{~min}, 5 \%$ within 90 min and $10 \%$ within $45 \mathrm{~min}$. A faster reduction is observed under sunlight because the composite has a band gap in the visible region. 
RASĀYAN J. Chem.

Vol. 13 | No. 4 |2616-2625| October - December | 2020

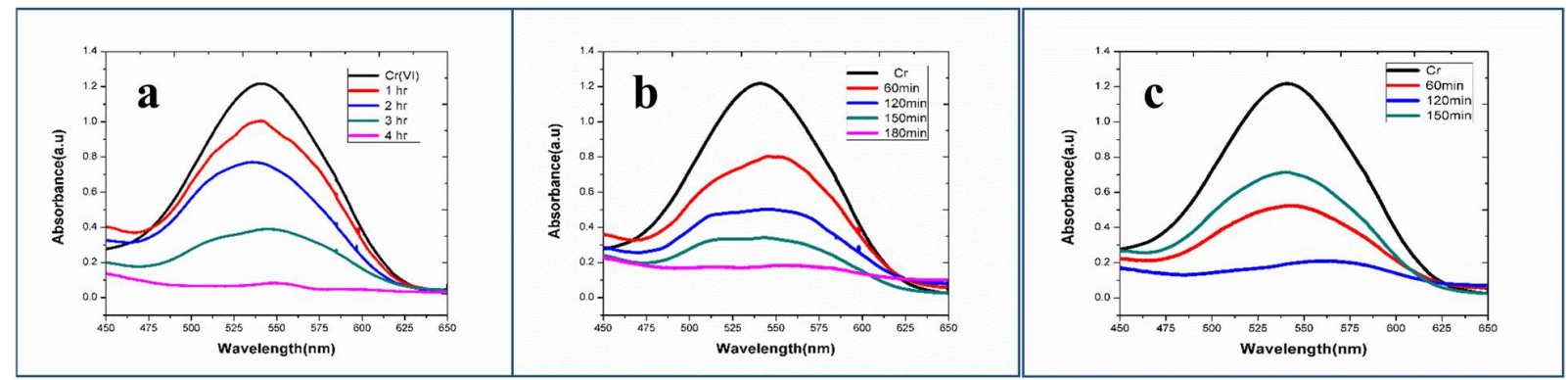

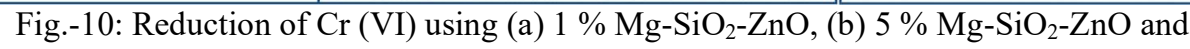

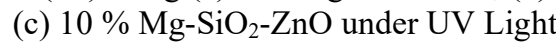

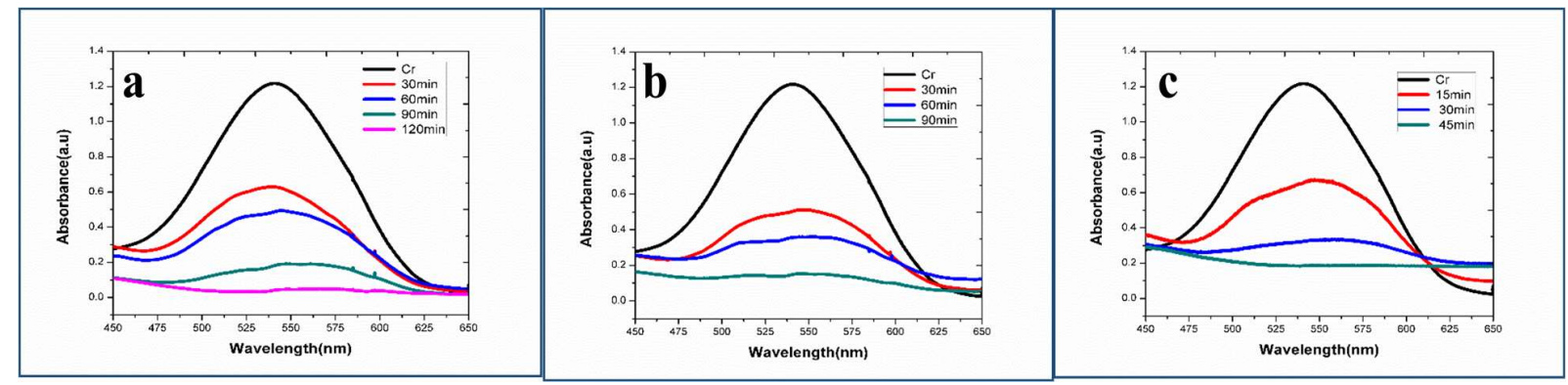

Fig.-11: Reduction of $\mathrm{Cr}$ (VI) using (a) $1 \% \mathrm{Mg}_{-} \mathrm{SiO}_{2}-\mathrm{ZnO}$, (b) $5 \% \mathrm{Mg}_{-} \mathrm{SiO}_{2}-\mathrm{ZnO}$ and (c) $10 \% \mathrm{Mg}-\mathrm{SiO}_{2}-\mathrm{ZnO}$ under Sunlight

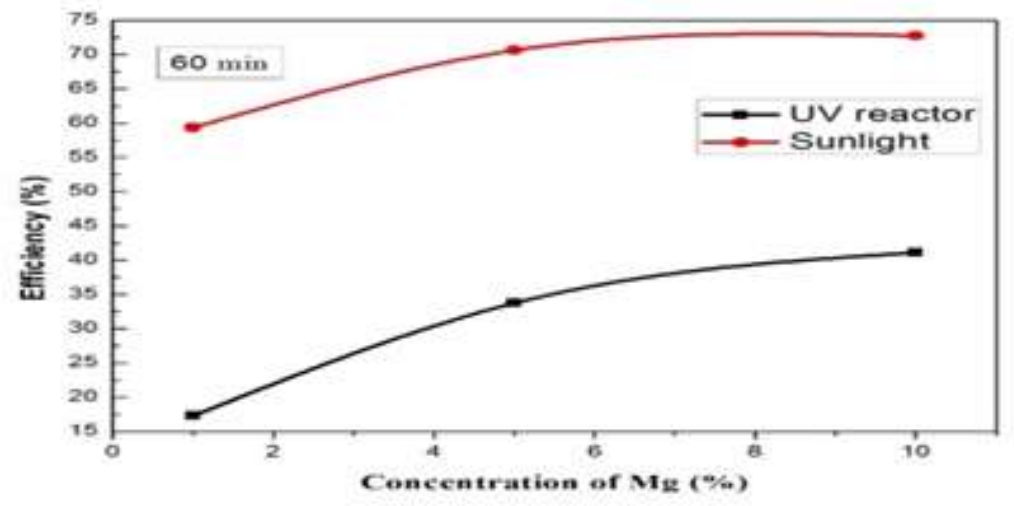

Fig.-12: Reduction Rate Variation with Doping Concentration

Doping has an important role in this photocatalytic reduction. It can be observed the time of reduction decreases as the doping concentration increases. The Fig.-12 shows the variation of efficiency with doping concentration at a constant time $(60 \mathrm{~min})$. The efficiency of reduction increases with an increase in doping concentration. Under UV, efficiency increases from $17.28 \%$ to $41.09 \%$ for an increase in doping concentration from $1 \%$ to $10 \%$. Similarly, under sunlight, there is an increase from $59.34 \%$ to $72.75 \%$.

In comparison with the relatively slow reduction of $\mathrm{Cr}(\mathrm{VI})$ in $\mathrm{UV}$, reduction accelerates under sunlight. This is because the optical band gap of nanocomposite is at the absorption range of visible light. The Fig.12 shows that the efficiency of the reduction under sunlight is higher than that under UV. The efficiency for $1 \%$ composite under sunlight is $59.3 \%$ whereas that under UV is $17.28 \%$. Similarly, there is a tremendous increase in efficiency for other samples under sunlight. As doping concentration increases, more vacancies are produced. These vacancies increase the number of electrons in the conduction band separating electron-hole pairs with the help of hole-scavengers. These electrons after getting excited from the valance band to the conduction band make reduction faster. ${ }^{9}$

Methylene blue degradation was also a successful application of $\mathrm{Mg}-\mathrm{SiO}_{2}-\mathrm{ZnO}$ nanocomposite. Under sunlight, $0.01 \%$ methylene blue (MB) degradation is possible with $1 \% \mathrm{Mg}-\mathrm{SiO}_{2}-\mathrm{ZnO}$. Major peaks of 
RASĀYAN J. Chem.

Vol. 13 | No. 4 |2616-2625| October - December | 2020

MB are observed at $617 \mathrm{~nm}$ and $657 \mathrm{~nm}$ as shown in the Fig.-13. Within a time of $8 \mathrm{~h}$, degradation of MB into small organic compounds was well analyzed from the decrease in absorption of sunlight. These intermediate organic compounds decompose to harmless inorganic anions such as chlorides, sulfides, and nitrates. Being a cationic dye, MB acquires electrons. The electrons disrupt its conjugated system leading to destruction. Holes in the valance band generate $\mathrm{OH}^{*}$ reacting with water or $\mathrm{OH}^{-}$ion. ${ }^{10}$

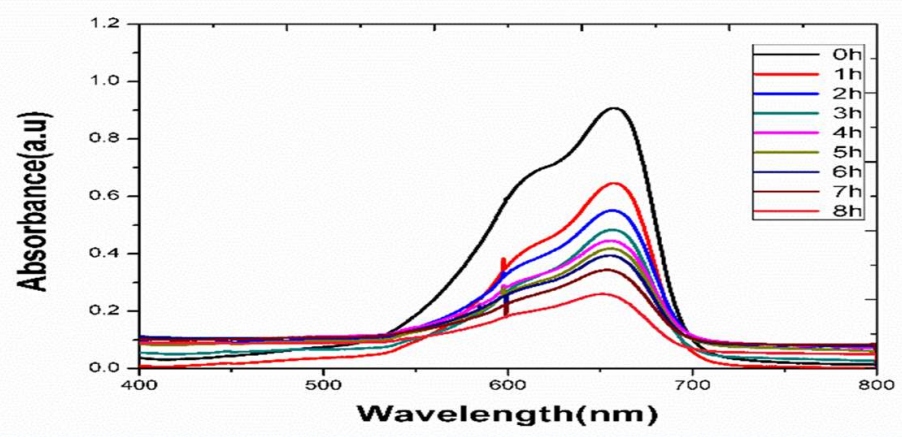

Fig.-13: Methylene Blue Degradation using 1\% $\mathrm{Mg}_{-} \mathrm{SiO}_{2}-\mathrm{ZnO}$ under Sunlight<smiles>CN(C)c1ccc2nc3ccc(=[N+](C)C)cc-3sc2c1</smiles>

Fig.-14: Structure of Methylene Blue

Methylene blue has a structure as shown in the Fig.-14. A lone pair of electrons are present in the N-S heterocyclic group. This electron pair enters in a reaction with highly reactive $\mathrm{OH}^{*}$, which destroys the conjugated heterocycle. As a result of which the absorption peaks in the UV-vis spectrum decreased ${ }^{11}$. So, this nanocomposite acts as an efficient photocatalyst for the reduction of $\mathrm{Cr}$ (VI) and the degradation of methylene blue.

\section{CONCLUSION}

The acidity of zinc sulfate and the basicity of sodium silicate resulted in the synthesis of $\mathrm{ZnO}$ and $\mathrm{SiO}_{2}$, where the incorporation of $\mathrm{Mg}$ enhances the property in $\mathrm{Mg}-\mathrm{SiO}_{2}-\mathrm{ZnO}$ tri-component nanocomposite. Advanced and cost-effective synthesis of $\mathrm{ZnO}$ and $\mathrm{Mg}_{-} \mathrm{SiO}_{2}-\mathrm{ZnO}$ by co-precipitation method revealed improved properties. $\mathrm{ZnO}$ is crystalline, whereas the nanocomposite is amorphous. The optical bandgap of the nanocomposite varies in the range of $2.4-2.6 \mathrm{eV}$. The FE-SEM image shows a nano-flake structure for $\mathrm{ZnO}$ with agglomeration and grain size in the nanometer range. The EDX plot reveals the presence of each element of the nanocomposite. The use of foxtail millet husk ash as a source of silica is proved to be a good choice. From XRF data analysis, the ash contains $91.1 \%$ of $\mathrm{SiO}_{2}$ and all other elements are at trace level. Acceleration in the photocatalytic degradation using the prepared nanocomposite may be due to the increase in defects with doping and increase in the surface area offered by silica which has a porous nature. Chromium (VI) is reduced to chromium (III) at a faster rate in the presence of sunlight than UV with the prepared nanocomposite as the photocatalyst. It also reduces methylene blue, one of the hazardous dyes in polluted water, in the presence of sunlight. So, this nanocomposite with enhanced properties enables it to be used as a versatile component for industrial applications.

\section{ACKNOWLEDGEMENT}

The author, K. M. Sreekanth acknowledges the support through AMRITA/IFRP-26/2015/16/08 of Amrita Vishwa Vidyapeetham.

\section{REFERENCES}

1. U. Sachin Varma, P. Gautham, D. V. Ravi Kumar, K. M. Sreekanth, G. Sivasubramanian and K. M. Sreedhar, Rasayan Journal of Chemistry, 11(4), 1491(2018), DOI:10.31788/RJC.2018.1144000 
RASĀYAN J. Chem.

Vol. 13 | No. 4 |2616-2625| October - December | 2020

2. K. Byrappa, A. K. Subramani, S. Ananda, K. M. Lokanatha Rai and R. Dinesh, Bulletin of Materials Science, 29, 433(2006), DOI:10.1007/BF02914073

3. M. Pratap Reddy, A. Venugopal and M. Subrahmanyam, Applied Catalysis B: Environmental, 69(34), 164 (2007), DOI:10.1016/ j.apcatb. 2006. 07.003

4. Haixia Tong, Xican Tao, Wu Daoxin, Xiongfei Zhang, Dan Li and Ling Zhang, Journal of Alloys and Compounds, 586, 274(2014), DOI:10.1016/j. jallcom. 2013.09.177

5. M. Swaminathan, N. Sobana and B. Krishnakumar, Materials Science in Semiconductor Processing, 16(3), 1046(2013), DOI:10.1016/j.mssp.2013.01.002

6. G. Sivasubramanian, C. Shanmugam and V. R. Parameswaran, Journal of Porous Materials, 20, 417(2013), DOI:10.1007/s10934-012-9611-0

7. U. Kalapathi, A. Proctor and J. Shultz, Bioresource Technology, 73, 257(2000), DOI:10.1016/S09608524(99)00127-3

8. M. Rouchdi, E. Salmani, B. Fares, N. Hassanain and A. Mzerd, Results in Physics, 7, 620(2017), DOI: 10.1016/j.rinp.2017.01.023

9. P. Gautham, U. Sachin Varma, K. M. Sreekanth, D. V. Ravikumar, K. M. Sreedhar and G. Sivasubramanian, Asian Journal of Chemistry, 30, 2631(2018), DOI:10.14233/ajchem.2018.21488

10. M. L. Curri, R. Comparelli, P. D. Cozzoli, G. Mascolo and A. Agostiano, Materials Science and Engineering, 23(1-2), 285(2003), DOI:10.1016/ S0928-4931(02)00250-3

11. Xi-Quan WANG, Song-fu HAN, Qing-wen Zhang, Nan Zhang and Dan-dan ZHAO, MATEC Web of Conferences, 238(3), 03006(2018), DOI:10.1051/ matecconf/201823803006

12. P. S. Mukherjee and A. K. Ray, Chemical Engineering and Technology, 22, 253(1999), DOI: $10.4236 /$ oalib.1100713

13. Sreekanth K. Mahadeva, Ph. D. Thesis, Department of Material Science and Engineering, KTH-The Royal Institute of Technology, Stockholm, Sweden, (2013)

14. Parmod Kumar, Hitendra K. Malik, Anima Ghosh, R. Thangavel and K. Asokan, Applied Physics Letters, 102, 221903(2013), DOI:10.1063/1.4809575

15. S. Suwanboon, P. Amornpitoksuk, A. Haidoux and J. C. Tedenac, Journal of Alloys and Compounds, 462(1-2), 335(2008), DOI:10.1016/ j.jallcom. 2007. 08.048

16. Samson B. Woodley, Alexey A. Sokol, Richard A. Catlow, Abdullah A. Al-Sunaidi and M. Scott, Journal of Physical Chemistry C, 117(51), 27127(2013), DOI:10.1021/jp4084635

17. T. A. Arun, Daya K. Chacko, Asha Anish Madhavan, T. G. Deepak, G. S. Anjusree, Thomas Sara, Seeram Ramakrishna, Shantikumar V. Naira and A. Sreekumaran Nair, Royal Society of Chemistry Advances, 4, 1421(2014), DOI:10.1039/C3RA45021 J

18. P. Amornpitoksuk, S. Suwanboon, S. Sangkanu, A. Sukhoom, N. Muensitand and J. Baltrusaitis, Powder Technology, 219, 158(2012), DOI:10.1016/ j.powtec.2011.12.032

19. Sumetha Suwanboon, Pongsaton Amornpitoksuk, Apinya Sukolrat and Nantakan Muensit, Ceramics International, 39(3), 2811(2013), DOI:10.1016/j.ceramint.2012.09.050

20. K. Ravichandran, P. Sathish, S. Snega, K. Karthika, P. V. Rajkumar, K. Subha and B. Sakthivel, Powder Technology, 274, 250(2015), DOI:10.1016/ j.powtec.2014.12.053

21. K. Ravichandran, S. Snega, N. Jabena Begum, L. Rene Christena, S. Dheivamalar and K. Swaminathan, Philosophical Magazine, 94(22), 2541(2014), DOI: 10.1080/14786435.2014.921349

22. Adil and Al-Mayouf, Journal of Saudi Chemical Society, 19(5), 462(2015), DOI: $10.1016 /$ j.jscs.2015.04.003

23. J. C. Fan, K. M. Sreekanth, Z. Xie, S. L. Chang and K. V. Rao, Progress in Materials Science, 58(6), 874(2013), DOI:10.1016/j.pmatsci.2013.03.002

24. Zhibin Wu, Xingzhong Yuan, Jin Zhang, Hou Wang, Longbo Jiang, and Guangming Zeng, Chem Cat Chem, 9(1), 41(2016), DOI:10.1002/cctc. 201600808

25. Ravikiran Nagarjuna, Swapna Challagulla, Ramakrishnan Ganesan and Sounak Roy, Chemical Engineering Journal, 308, 59(2016), DOI:10.1016/ j.cej. 2016.09.044

26. S. Hiller and D. G. Lumsdon, Clay Minerals, 43, 477(2008), DOI:10.1180/claymin.2008.043.3.11

[RJC-5859/2020] 